\title{
Person Telecom Address
}

National Cancer Institute

\section{Source}

National Cancer Institute. Person Telecom Address. NCI Thesaurus. Code C94273.

A sequence of digits or characters used to identify a particular telephone, fax, or email of the person. 